\title{
G

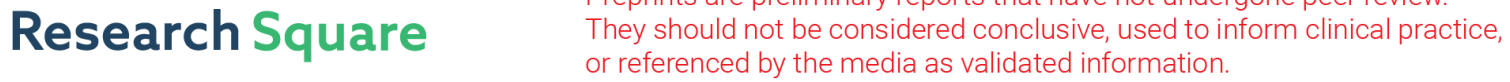 \\ Feasibility for SARS-CoV-2 Tests in the Hospital: An Exposure Analysis of Critical Control Points Approach
}

\section{Tingting Feng ( $\nabla$ ycttfeng@163.com )}

Department of Clinical Pharmacy, Shanghai General Hospital

\section{Sebastian Leptihn}

Zhejiang University-University of Edinburgh Institute (ZJU-UoE), Zhejiang University

\section{Mingyue Li}

Department of Pathology and Laboratory Medicine, Perelman School of Medicine, University of

Pennsylvania, Philadelphia

\section{Mingquan Guo}

Shanghai Institute of Phage, Shanghai Public Health Clinical Center, Fudan University

\section{Jing Gao}

Department of Clinical Laboratory, Obstetrics and Gynecology Hospital of Fudan University

\section{Qingtian Li}

Department of Laboratory Medicine, Ruijin Hospital, Shanghai Jiao Tong University School of Medicine lingbing Zeng

Department of Clinical Laboratory, the First Affiliated Hospital of Nanchang University

\section{Yuhua Zhou}

Department of Emergency Medicine, Ruijin Hospital, Shanghai Jiao Tong University School of Medicine, Shanghai 200025

\section{Yanxia Wei}

Jiangsu Key Laboratory of Immunity and Metabolism, Laboratory of Infection and Immunity, Department of Pathogenic Biology and Immunology, Xuzhou Medical University

\section{Xiaokui Guo}

Department of Immunology and Microbiology, School of Medicine, Shanghai Jiao Tong University

\section{Nigel Temperton}

Viral Pseudotype Unit, Medway School of Pharmacy, University of Kent

\section{Zelin Cui ( $\nabla$ czl@sjtu.edu.cn )}

Shanghai General Hospital https://orcid.org/0000-0002-2700-5800

\section{Research}


Keywords: Coronavirus disease 19, Severe acute respiratory syndrome coronavirus 2, Hospital, Test, Fever clinic

Posted Date: June 4th, 2021

DOI: https://doi.org/10.21203/rs.3.rs-33080/v2

License: (c) (1) This work is licensed under a Creative Commons Attribution 4.0 International License. Read Full License 


\section{Abstract}

This work aims to assess the feasibility of performing COVID-19 RNA tests in hospitals and communities experiencing SARS-CoV-2 virus outbreaks, to ultimately provide recommendations for hospitals with socalled fever clinics. In China, these specialized clinics within a hospital specifically receive outpatients with fever symptoms. A team with expertise in the Exposure Analysis and Critical Control Points (EACCP) framework identified potential infection routes during the testing for SARS-CoV-2, then constructed and tested flow diagrams, which were confirmed under actual conditions, demonstrating the feasibility to carry out in hospitals with fever clinics. The team determined critical control points to mitigate the exposure risks at each control point. The sampling and inactivation steps of clinical samples in fever clinics appeared to be associated with particularly high-risk levels of exposure to SARS-CoV-2. Moderate exposure levels were associated with storage and transportation of samples for inactivation; Low-risk levels associated with the transportation, storage, and detection steps after inactivation. To minimize infection risks for personnel, we proposed optimized processes to carry out SARS-CoV-2 RNA tests in hospitals with fever clinics in China. The high risk of SARS-CoV-2 exposure during procedures preceding testing is the sampling and biological inactivation; Simultaneously, full personal protective equipment and BSL2 laboratories in fever clinics or mobile BSL2 laboratories could reduce the risk. Implementing the EACCP framework could facilitate rapid responses to outbreaks of emerging infectious diseases.

\section{Introduction}

Infectious diseases have shaped the course of human history and continue to do so, with new emerging diseases being a threat more than ever to humankind. The COVID-19, which caused by the SARS-CoV-2 caught local and global healthcare communities unaware and unprepared ${ }^{[1-2]}$. By Jul $3^{\text {th }}, 2020$, the pandemic had associated with at least 10,906,822 confirmed, probable, or suspected cases - reported in 188 countries/regions - and 522,112 deaths (https://coronavirus.jhu.edu/map.html). Before SARS-CoV-2, other emerging infectious disease outbreaks, such as SARS in 2003 , presented extraordinary challenges to healthcare systems and governments worldwide. One of the challenges is to test thousands of samples every day to excluded suspected patients, which is a critical marker for the management of an outbreak- especially in the communities of big cities which are transportation hubs ${ }^{[3-4]}$. Highly pathogenic viruses such as SARS-CoV-2 are usually tested in Centers for Disease Control (CDC) and other authorized agencies with the biosafety level 3 (BSL3) protection during outbreaks ${ }^{[5]}$. In contrast, such tests are often not authorized to be carried out in hospitals even if BSL2 laboratories ${ }^{[6-7]}{ }^{[8]}$ are available. However, long distances between hospitals receiving COVID-19 patients and authorized agencies conducting tests require the samples to be stored and transported under appropriate conditions for two main reasons: (a) to reduce infection risks of personnel handling the samples and (b) to avoid degradation of nucleic acids, which was one of the main reasons for false negatives of SARS-CoV-2 RNA tests at the beginning of COVID-19 endemic in Wuhan ${ }^{[9]}$. Fortunately, nearly all hospitals with fever clinics are equipped with BSL2 laboratories to perform molecular biology tests, including PCR, reverse transcription PCR, and real-time PCR. BSL2 laboratories in hospitals to carry out RNA tests during a 
pandemic would support both patients' management and the outbreak itself. These RNA test results are crucial for proper scientific management of many patients who might have contracted the virus ("suspected cases") that have to be screened every day during the outbreak. The testing and results are also critical in determining whether a patient has recovered and is still shedding viruses.

According to guidelines from the "Office of the National Health Council Office of the National Administration of Chinese Medicine" (ONCONACM) ${ }^{[10]}$, procedures that do not propagate biological material (e. g. the cultivation of pathogens or production of viruses) such as antigen tests, sera tests, RNA extraction, and samples inactivation, can be carried out in the BSL2 laboratories with BSL3 personal protection. Departments of laboratory medicine in Chinese hospitals generally carry out lots of diagnostic tests using biochemical or immunological methods, or molecular biology, microbiology and cell biology techniques, with clinical diagnostic testing in the same facility; here, a high number of clinical staff is present at the same time, making it potentially dangerous for handling infectious agents. In this case, they require all operators to wear BSL3 protection due to pathogen transmission risks, which might present a logistical and financial burden, mostly due to the shortage of personal protective equipment (PPE) during outbreaks. Therefore, one of the main reasons preventing SARS-CoV-2 tests from being carried out in a hospital laboratory is the potential SARS-CoV-2 exposure risks in this setting. Many diagnostic tests have already been carried out regularly in Chinese hospitals' clinical laboratories. The biological material was inactivated first before testing. An example is a test for tuberculosis performed in BLS2 laboratories; here, the samples from patients infected by Mycobacterium tuberculosis are inactivated by heating before the Ziehl-Neelsen acid-fast staining, thus no infection risk for the operator.

Hazard Analysis and Critical Control Points (HACCP) was initially developed for food production systems ${ }^{[11]}$, but was successfully adapted to manage and mitigate the exposure risks associated with detecting pathogens in clinical settings. They use it to reduce the risks related to emerging infectious diseases and other health threats ${ }^{[12-13]}$. Since its use is both low-technology and comparably inexpensive, the framework may be instrumental in addressing the risks associated with emerging infectious disease in areas where the capacity of existing healthcare systems is insufficient to cope with the impact of a health crisis such as an epidemic ${ }^{[14-15]}$. The framework's methods encourage interdisciplinary expertise while enabling the rapid generation of evidence-based recommendations to assess the feasibility of carrying out the SARS-CoV-2 RNA test in the hospital with a fever clinic. Therefore, it offers the potential to manage risks when the rapid control of an outbreak is essential, especially with infection rates for healthcare workers at the early stage of the COVID-19 outbreak being relatively high. Here we bring Exposure Analysis and Critical Control Points (EACCP) concept forward to assess the exposures in an infectious disease area. In the present study, we evaluated the EACCP and its feasibility regarding SARS-CoV-2 exposures risks posed by diagnostic procedures and generated recommendations for carrying out SARS-CoV-2 RNA tests in hospitals' EACCP framework.

Our work devised a process for each step to test SARS-CoV-2 RNA and evaluated the process's feasibility to be carried out safely in hospitals. We assessed the infection exposure risk in each step and generated the whole procedure's critical control points. Simultaneously, we established the PPE 
requirements and generated recommendations for clinics and mobile testing facilities. We then evaluated their potential for the EACCPs framework as a response tool during outbreaks of emerging infectious diseases. Here, exposure, i.e., the close contact to patients possibly infected with SARS-CoV-2 to obtain samples, poses high direct transmission risks. We identified other possible sources for direct or indirect transmission of the SARS-CoV-2 virus during various procedures associated with sampling, sample storage, and transport, as well as inactivation. Finally, we evaluated our assessments' potential use to be implemented in the EACCP framework as a response tool during an outbreak of an emerging infectious disease.

\section{Methods}

\subsection{Principles}

In conducting our EACCP, we adapted the guidance (HACCP) within an annex to the Codex Alimentarius Commission's General Principles of Food Hygiene ${ }^{[13-16]}$. Although this guidance refers to 12 steps in the analysis, we disregarded later steps because our procedure, implementing the recommended control measures or establishing the subsequent on-the-ground monitoring, is not required (Fig.1). We used a seven-step process similar to the one used for highly pathogenic avian influenza ${ }^{[14]}$. The seven steps are: (i) Assemble a team with appropriate expertise in EACCP; (ii) identify clinical samples from the potential COVID-19 patients for RNA tests; (iii) construct flow diagrams illustrating the system of care; (iv) test and confirm the accuracy of each flow diagram; (v) list potential virus exposure associated with each step in each flow diagram and conduct a virus exposure analysis; (vi) determine critical control points, and (vii) establish critical limits for each critical control point.

\subsection{Team}

The international and multidisciplinary nature of the problems posed by the SARS-CoV-2 virus meant that we - i.e., the members of the research team - were obliged to conduct our analysis via a mixture of online meetings and email exchanges. The research team included experts in emergency medicine, laboratory medicine, HACCP protocols, medical microbiology, virology, epidemiology, and biosafety. The team members are from 12 different institutional departments spread across multiple institutes and hospitals within China, the USA, and the United Kingdom. Our analysis began when team members from the Shanghai Jiaotong University held a series of small online meetings. We then shared the progress made in these meetings with a broader group of team members for comment and feedback.

\subsection{Process}

A systematic approach allows for expert opinion synthesis with their knowledge in the analysis. It might provide clarity on the topic of public health. In our early meetings, we concentrated on defining the most crucial exposure operations - in terms of the risk of exposures to pathogen material-and then created initial flow diagrams representing the pathways for sampling and RNA tests in the hospitals (Fig.2). The diagrams were then shared with the other team members - with further colleagues' 
involvement so that a wider group of experts could comment on them - before they were reviewed and simplified. Experts from medicine, biosafety, molecular biology, infectious medicine, and medical microbiology provided their views on the flow diagrams. This review and a final critical analysis by an international panel of experts led to further modifications to - and simplifying - the diagrams.

We considered exposure to be a process - within a hospital with patients possibly infected by SARSCoV-2 - that could lead to exposure to the virus or provide the opportunity for transmission of the SARSCoV-2 to another person. We grouped the exposures into high-, medium- and low-risk categories to evaluate the likely exposure scenarios. Following the validation of each flow diagram, the research team determined appropriate critical control points - i.e., the points at which there is an opportunity to reduce or eliminate virus exposure risks. The team then created so-called critical limits, for each identified critical control point, based on expert knowledge (Fig.1), followed by the validation via an analysis of the relevant published data on the epidemiology, prevention, and control of COVID-19 and the current relevant recommendations from the World Health Organization (WHO) ${ }^{[17]}$.

\subsection{Feasibility of implementation and recommendations for procedures}

We used the analysis results to evaluate the feasibility of implementing our procedure and develop recommendations to carry out COVID-19 RNA tests in the hospitals. On Apr 19, 2020, the Chinese government announced and required Grade A hospitals to carry out the SARS-CoV-2 RNA test; the grade A hospitals in Shanghai (e.g., Shanghai General Hospital) have already been carried out SARS-CoV-2 RNA test since Apr 20. 2020. The patients for testing were sampled at the fever clinic and stored with agents that could inactivation SARS-CoV-2, then delivered to the BSL2 laboratories for the test following the requirements of UN2814.

\section{Results}

\subsection{Exposure analysis}

Our assessment of the feasibility for SARS-CoV-2 RNA tests in the hospital within hospital settings affected by the SARS-CoV-2 virus revealed multiple exposure practices linked to the sampling, storage, transportation, inactivation, and transport subsequent analysis of samples from potential COVID-19 patients (Table 1 and Fig.2). If managed poorly, we believe that each of these operations presents an unacceptable level of risk of transmitting the virus.

We categorized as high-risk involved potential directly exposures to SARS-CoV-2: the sampling and inactivation procedures (Fig.2). The practices identified as medium-risk involved indirect exposures such as the storage and transportation of samples for disinfection (Table 1). All of the other activities and practices linked to operation after the samples' inactivation present a low-risk of transmitting the virus.

\subsection{Control points and limits}


We identified four critical control points- i.e., 4 points at which there is an opportunity to adopt measures to reduce exposure risks. Following extensive consultation and cross-referencing with the existing literature, we identified one or more potential exposure risks for each such point and then established one or more recommendations to increase the feasibility of reducing each step's exposure risk (Table 1). The critical control points identified could be assigned to one of five categories: sampling from patients potentially suffering from COVID-19, sample storage, transportation for inactivation, or inactivation. The recommendations that we made for each critical control point derive from a combination of essential exposure control, but also to keep SARS-CoV-2 RNA material intact for reliable subsequent analysis, such as (i) employing BSL-3 protection for the healthcare workers who take samples from the patients and inactivate samples to reduce exposure risk and (ii) avoiding physical, chemical and biological factors that might lead to RNA degradation. Next, analyzing existing literature and SARS-CoV-2 RNA test recommendations, we suggest procedure-related changes that could reduce the false negative due to RNA degradation. Several of the recommendations we made include fundamental aspects of infection prevention and control - e.g., the correct and proper use of full personal protective equipment, appropriate storage and transportation, and the proper disinfection operation using UV, heating equipment and followed by the use of appropriate disinfectants for inactivation, the materials of transport boxes or sample containers; most importantly, RNA degradation inhibitors should be prepared and ready before sampling.

\section{Discussion}

The present study based on the EACCPs framework assessed the feasibility of implementing new or optimized processes. It made recommendations for the protection of health workers and other staff in health facilities as well as the broader public from the risks of exposures that occur during the sampling of sputum, oropharyngeal swabs, bronchoalveolar lavage fluid (BALF), blood or feces of (suspected) COVID-19 patients for SARS-CoV-2 RNA tests. During this analysis, we identified four critical control points associated with the sampling, storage, transportation, and inactivation of the samples from COVID-19 susceptible patients; the required individual BSL3 protection measures for these operations were identified. The first three (sampling, transportation, and storage) have been all already available in [fever] clinics in hospitals in China; furthermore, most clinical laboratories of hospitals are equipped with BSL2 laboratories providing the possibility to conduct RNA tests.

Our analysis took state-of-the-art and present knowledge described in the published literature and guidelines published by the Chinese national or international organizations associated with the inactivation of SARS-CoV-2 for RNA tests into account. The framework allows for the rapid identification of the risks associated with known exposure. The existing conditions that prevent SARS-CoV-2 tests from being conducted in the laboratories of clinics mainly result in the potential SARS-CoV-2 exposure to all staff, with some not even involved in the testing for COVID-19. One of the most critical control points would be to avoid a down-process risk altogether by inactivating the samples before sending them for the test to establish a safe, robust, and reliable testing procedure. Therefore, we propose that the inactivation of the SARS-CoV-2 samples should be performed in the fever clinics BSL2, mobile BSL2 laboratories 
(Fig.3), or the sampling tubes with inactivation agents. To summarize: to effectively combat any infectious disease outbreak in the future, BSL2 laboratories (or higher) -whether in hospitals or mobile facilities- with individuals equipped with BSL3 protection should be used for sample inactivation.

Besides the general requirement to establish BSL2 laboratories, a $56^{\circ} \mathrm{C}$ heating system or preloaded sampling tubes including agents for inactivation of samples inside of tubes or bottles are required; Besides, disinfectants (such as $70 \%$ ethanol) for disinfection outside of the tubes or bottles or inside or outside of the box for transportation, and UV violet for surface disinfection, are also needed. It is well established that heat treatment of $56^{\circ} \mathrm{C}$ for $60 \mathrm{~min}$ or UV violet radiation for $15 \mathrm{~min}$ are both able to deactivate SARS-CoV-2 viruses or reduce their infectivity to superficial level ${ }^{[18]}$. Also, suitable individual protection equipment provides sufficient protection to the Risk of Exposure. After inactivation (e.g., by heat treatment), the samples can now be transferred for RNA tests into a standard BSL2 molecular laboratory, commonly found in many hospitals with infection medicine. As the samples are inactivated and present no or negligible risk of transmission, it is not required to perform the tests exclusively by the CDC or other authorized agencies; if the hospitals receiving susceptible COVID-19 patients could perform the test, this would massively accelerate the screening for suspected COVID-19 cases during an outbreak. SARS-CoV-2 infected more than 1716 local healthcare workers in the hospital till Feb 14, 2020, 87.5\% of them in Wuhan (Mar 8, 2020 reports from ONCONACM). It is likely to have happened due to SARS-CoV-2 transmissions allowed by insufficient protection at the beginning of endemic; soon after that, more than 42600 healthcare workers supporting Wuhan, and no infections occurred among them due to sufficient protection (Mar 8, 2020 reports from ONCONACM). It indicates that appropriate individual protection is sufficient to avoid exposure during various procedures with patients and patient samples and shows the potential feasibility of carrying out the hospitals' screening. A study showed that samples inactivated by heating could lower positive test results and might increase the $\mathrm{Ct}$ value ${ }^{[19]}$. Another report showed that the agents inhibiting RNA degradation during sampling could prevent negative test results of COVID-19 patient samples [20]; this implies that, for COVID-19 RNA tests, the choice of proper inactivating procedures is crucial for high accuracy of test results.

The response and management to the pandemic's challenge vary from country to country due to resources, governmental structures, and population compliance. Rapid and accurate diagnoses and monitoring of SARS-CoV-2 infections have shown to be crucial for effective control of the current outbreak $^{[21]}$. Similar to the Fangcang shelters for treating the diagnosed COVID-19 patients with mild symptoms ${ }^{[22]}$. It is essential to avoid cross-transmission of disease agents such as other viruses or pathogenic bacteria in the waiting room before sampling for testing. For developed countries like the USA, which are often less densely populated than China and Korea (Figure3 and Table2), almost every family has a privately owned car. Setting up "drive-through" test sites is convenient for the potentially infected person and reduces the risk of being infected with pathogens while also presenting a safe solution for the healthcare workers performing the test. For developed countries such as South-Korea that are densely populated, privately owned vehicles are often available; in addition to the "drive-through" test sites, hospital-based or mobile platforms were required for efficient testing who cannot use a car. In contrast to 
this, Chinese citizens often do not own a car; therefore, it is unrealistic to carry out "drive-through" tests to cover most of the population and not just a section.

During the SARS-CoV-2 outbreak, hospitals in big cities like Shanghai and Zhengzhou received hundreds of outpatients in their fever clinics daily; to avoid cross-transmission in waiting rooms of the hospitals. Zhongshan hospital in Shanghai set up two separate fever clinics, one specifically for suspected COVID-19 cases. Here, they sampled the patients and then sent samples to the CDC or another authorized agency for processing and testing. As the designated hospital receiving COVID-19 patients, the Zhengzhou First People's hospital converted the BSL2 laboratory into a fever clinic. They can test the suspected cases timely, avoiding waiting for the results for a long time after sending them out for RNA test.

Furthermore, commercial entities started developing systems to participate in the testing for the SARS-CoV-2 virus; an example is the "Fire eye" mobile BSL2 laboratory developed by BGI for the detection of viral RNA include the process from sampling to testing. In Germany and the USA, private companies also participate in the testing for the coronavirus and governmentally financed research institutes like the Robert Koch Institute in Germany that contribute to testing. Besides, the German government sought the Institute for testing and the containment of the SARS-CoV-2 virus to decrease the number of infections in the population.

\section{Conclusion}

In conclusion, our analysis has shown that it is feasible to carry out SARS-CoV-2 RNA tests in hospitals. Different transmission risks are associated with sampling, sample storage, and transportation, as well as with inactivation for subsequent tests of samples from patients potentially suffering from COVID-19. Procedures include sampling (high risk), storage (medium risk), and transportation (medium risk) have already been existing in hospitals. The feasibility to use existing BSL2 laboratories in hospitals, which were widely available in large cities in China during the COVID-19 outbreak, require one crucial step: The inactivation of the samples, a high-risk operation, has to be performed in clinics or mobile facilities using BSL2 laboratories, but with BSL3 protection provided for all the operators and other personnel presents. If implemented, this process would massively decrease the CDC's test burden during the outbreak of COVID19 and lay a part of the foundations for thorough preparation for the emergence of the next infectious disease outbreak in the future.

\section{Abbreviation}

Exposure Analysis of Critical Control Points (EACCP); Hazard Analysis and Critical Control Points (HACCP); personal protective equipment (PPE); Office of the National Health Council Office of the National Administration of Chinese Medicine (ONCONACM).

\section{Declarations}




\section{Ethics approval and consent to participate}

Not Applicable.

\section{Consent for publication}

All authors contributed significantly to the work, and saw the manuscript and approved to submit to the journal.

\section{Competing interests}

The authors declare no conflicts in interests.

\section{Funding}

The soft fund for prevention and treatment of SARS-CoV-2 infection of Shanghai Jiaotong University (No.2020RK50), the outstanding medical youth program A of Shanghai General Hospital (No.06N1702002) and the Zhejiang University Special scientific research fund for COVID-19 prevention and control (2020XGZX037).

\section{Authors' contributions}

The study was conceived and designed by ZLC and TTF. The data were acquired by MQG, JG, YHZ, LBZ, YXW, QTL, and XKG; interpreted by ZLC, TTF initiated the study and ZLC coordinated and oversaw the study. The manuscript was drafted by TTF, ZLC. SL, MYL, NT and QTL revised for intellectual content and approved for publication by TTF, SL, MYL, JG, MQG, LBZ, QTL, YHZ, YXW, XKG and ZLC.

\section{Acknowledgements}

Thanks Junwei Zhao of Zhengzhou University for suggestion to improve the manuscript.

\section{Availability of data and material}

Not Applicable.

\section{References}

[1] Cucinotta D, Vanelli M. WHO Declares COVID-19 a Pandemic. Acta Biomed, 2020, 91(1): 157-160. 
[2] Zhu N, Zhang D, Wang W, Li X, Yang B, Song J, Zhao X, Huang B, Shi W, Lu R, Niu P, Zhan F, Ma X, Wang D, Xu W, Wu G, Gao GF, Tan W, China Novel Coronavirus I, Research T. A Novel Coronavirus from Patients with Pneumonia in China, 2019. N Engl J Med, 2020, 382(8): 727-733.

[3] Gao ZC. [Efficient management of novel coronavirus pneumonia by efficient prevention and control in scientific manner]. Zhonghua Jie He He Hu Xi Za Zhi, 2020, 43(3): 163-166.

[4] Peto J. Covid-19 mass testing facilities could end the epidemic rapidly. BMJ, 2020, 368: m1163.

[5] Chen W, Lan Y, Yuan X, Deng X, Li Y, Cai X, Li L, He R, Tan Y, Deng X, Gao M, Tang G, Zhao L, Wang J, Fan Q, Wen C, Tong Y, Tang Y, Hu F, Li F, Tang X. Detectable 2019-nCoV viral RNA in blood is a strong indicator for the further clinical severity. Emerg Microbes Infect, 2020, 9(1): 469-473.

[6] General biosafety standard for causative bacteria laboratories. WS233-2002, 2018.

[7] Laboratories-General requirements for biosafety. GB19489-2008, 2009.

[8] Guideline for clinical laboratory biosafety. WS/T 442-2014, 2014.

[9] Pan X, Chen D, Xia Y, Wu X, Li T, Ou X, Zhou L, Liu J. Asymptomatic cases in a family cluster with SARS-CoV-2 infection. Lancet Infect Dis, 2020, 20(4): 410-411.

[10] Pang J, Wang MX, Ang IYH, Tan SHX, Lewis RF, Chen JI, Gutierrez RA, Gwee SXW, Chua PEY, Yang Q, Ng XY, Yap RK, Tan HY, Teo YY, Tan CC, Cook AR, Yap JC, Hsu LY. Potential Rapid Diagnostics, Vaccine and Therapeutics for 2019 Novel Coronavirus (2019-nCoV): A Systematic Review. J Clin Med, 2020, 9(3).

[11] Bobeng BJ, David BD. HACCP Models for Quality Control of Entree Production in Foodservice Systems. J Food Prot, 1977, 40(9): 632-638.

[12] Di Renzo L, Colica C, Carraro A, Cenci Goga B, Marsella LT, Botta R, Colombo ML, Gratteri S, Chang TF, Droli M, Sarlo F, De Lorenzo A. Food safety and nutritional quality for the prevention of non communicable diseases: the Nutrient, hazard Analysis and Critical Control Point process (NACCP). $J$ Transl Med, 2015, 13: 128.

[13] Edmunds KL, Elrahman SA, Bell DJ, Brainard J, Dervisevic S, Fedha TP, Few R, Howard G, Lake I, Maes P, Matofari J, Minnigh H, Mohamedani AA, Montgomery M, Morter S, Muchiri E, Mudau LS, Mutua BM, Ndambuki JM, Pond K, Sobsey MD, van der Es M, Zeitoun M, Hunter PR. Recommendations for dealing with waste contaminated with Ebola virus: a Hazard Analysis of Critical Control Points approach. Bull World Health Organ, 2016, 94(6): 424-432.

[14] Edmunds KL, Hunter PR, Few R, Bell DJ. Hazard analysis of critical control points assessment as a tool to respond to emerging infectious disease outbreaks. PLoS One, 2013, 8(8): e72279. 
[15] Ye G, Pan Z, Pan Y, Deng Q, Chen L, Li J, Li Y, Wang X. Clinical characteristics of severe acute respiratory syndrome coronavirus 2 reactivation. $J$ Infect, 2020, 80(5): e14-e17.

[16] ORGANIZATION WH, NATIONS FAAOOTU. General principles of food hygiene, annex to CAC/RCP 1-1969. (Rev. 4 - 2003). Rome: Codex Alimentarius Commission, 2009.

[17] WHO. Laboratory biosafety guidance related to the novel coronavirus (2019-nCoV). 2020(2).

[18] Kariwa H, Fujii N, Takashima I. Inactivation of SARS coronavirus by means of povidone-iodine, physical conditions, and chemical reagents. Jpn J Vet Res, 2004, 52(3): 105-112.

[19] Xiuzhi D, Xuchu W, Pan Y, Weiwei L, Xiang L, Zhang Lele, Gong Z, Huqiang T, Qin C, Xianguo W, Zhihua T. Effect of virus inactivation on weak positive results of nucleic acid test for 2019 Novel Coronavirus. Chin J Lab Med, 2020(04): 358-362.

[20] Zhang Q, Zhao Q. Disinfection by heat-kill before RNA extraction could reduce the number of RNA templates that can be detected. chinaXiv:202002.00034 (or this versionchinaXiv:202002.00034V1), 2020.

[21] Tang YW, Schmitz JE, Persing DH, Stratton CW. Laboratory Diagnosis of COVID-19: Current Issues and Challenges. J Clin Microbiol, 2020, 58(6).

[22] Chen S, Zhang Z, Yang J, Wang J, Zhai X, Barnighausen T, Wang C. Fangcang shelter hospitals: a novel concept for responding to public health emergencies. Lancet, 2020, 395(10232): 1305-1314.

\section{Tables}


1. 1 Summary of the Exposure Analysis and Critical Control Point (EACCP) assessment for the COVID-19 A detection in the hospital with fever clinics in China

\begin{tabular}{|c|c|c|c|c|c|c|}
\hline \multirow[t]{2}{*}{$\begin{array}{l}\text { ential exposure by the } \\
\text { ical control point }\end{array}$} & \multicolumn{2}{|c|}{$\begin{array}{l}\text { Level of concern about } \\
\text { exposure }\end{array}$} & \multirow{2}{*}{$\begin{array}{l}\text { Individual } \\
\text { protection } \\
\text { level }\end{array}$} & \multirow[t]{2}{*}{ Feasibilities } & \multirow[t]{2}{*}{ CCPs } & \multirow[t]{2}{*}{$\begin{array}{l}\text { PPE and Key } \\
\text { requirements }\end{array}$} \\
\hline & Samples & $\begin{array}{l}\text { The surface of } \\
\text { Sampling tubes }\end{array}$ & & & & \\
\hline ampling & High & Medium & BSL3 & $\begin{array}{l}\text { Currently } \\
\text { Available }\end{array}$ & Yes & $\begin{array}{l}\text { - Face mask } \\
\text { - Medical } \\
\text { protective } \\
\text { clothing } \\
\text { - Glove } \\
\text { - Goggle } \\
\text { - Face shield }\end{array}$ \\
\hline $\begin{array}{l}\text { iample storage for } \\
\text { isport }\end{array}$ & Medium & Medium & BSL 2 & $\begin{array}{l}\text { Currently } \\
\text { Available }\end{array}$ & Yes & $\begin{array}{l}\text { - face shield } \\
\text { - Box } \\
\text { - Glove } \\
\text { - Goggle } \\
\text { - Medical } \\
\text { protective } \\
\text { clothing }\end{array}$ \\
\hline $\begin{array}{l}\text { iample transport for } \\
\text { nfection }\end{array}$ & Medium & Medium & BSL 2 & $\begin{array}{l}\text { Currently } \\
\text { Available }\end{array}$ & Yes & $\begin{array}{l}\text { - UV- and } \\
\text { heatproof box } \\
\text { - Disinfectant } \\
\text { (70\% ethanol) } \\
\text { - Goggle } \\
\text { - face shield } \\
\text { - Medical } \\
\text { protective } \\
\text { clothing }\end{array}$ \\
\hline iample disinfection & High & Medium & BSL 3 & $\begin{array}{l}\text { Not } \\
\text { available }\end{array}$ & Yes & $\begin{array}{l}\text { - BSL2 } \\
\text { laboratory } \\
\text { - Class II BSC } \\
\text { - Temperature } \\
\text { controllable } \\
\text { heater } \\
\text { - Goggle } \\
\text { - face shield } \\
\text { - Medical } \\
\text { protective } \\
\text { clothing }\end{array}$ \\
\hline ample test & Low & Low & BSL 2 & $\begin{array}{l}\text { Currently } \\
\text { available }\end{array}$ & No & $\begin{array}{l}\text { - Surgical face } \\
\text { mask } \\
\text { - Medical } \\
\text { isolation } \\
\text { garment } \\
\text { - glove }\end{array}$ \\
\hline
\end{tabular}


CCPs: critical control points,

PPE: Personal protective equipment,

BSL 3: Biosafety Level 3,

BSL 2: Biosafety level 2.

Tab. 2 Response modes of some countries for text suspected COVID-19 cases.

\begin{tabular}{llc}
\hline Countries/District & Modes & $\begin{array}{c}\text { Start } \\
\text { date }\end{array}$ \\
\hline $\begin{array}{l}\text { South Korea; USA; United } \\
\text { Kingdom; }\end{array}$ & Mobile BSL2 laboratory/"Driven through" test sites & $\begin{array}{l}\text { Feb } \\
27,2020\end{array}$ \\
$\begin{array}{l}\text { China; Serbia; United Arab } \\
\text { Emirates; }\end{array}$ & "Fire Eye" mobile BSL2 laboratory developed by BGI group & $\begin{array}{l}\text { Feb 5, } \\
\text { Brunei; Kingdom of Saudi }\end{array}$ \\
Arabia & & 2020 \\
Germany & Governmentally financed research institutes (e.g., Robert Koch & $/$ \\
& Institute) & $/$ \\
China (Shanghai) & Special Fever Clinic for COVID-19 cases in Zhongshan Hospital \\
China (Shanghai) & Particular sampling room for screening the patients in Shanghai & Apr 20, \\
& General hospital & 2020 \\
China (Zhengzhou) & BSL2 laboratory converted in Fever Clinic in First people's & Feb \\
& hospital of Zhengzhou & 13,2020 \\
USA & At home test & Apr 21, \\
& & 2020
\end{tabular}

"/" means unavailable

\section{Figures}


Q1 : Is there any SARS-Cov-2 exposure risk?
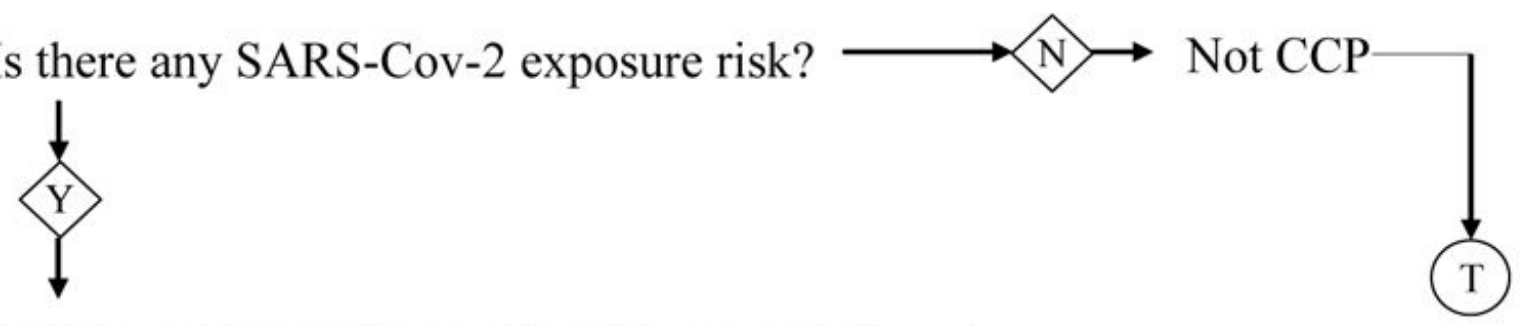

Q2: Is there any method to control the exposure?
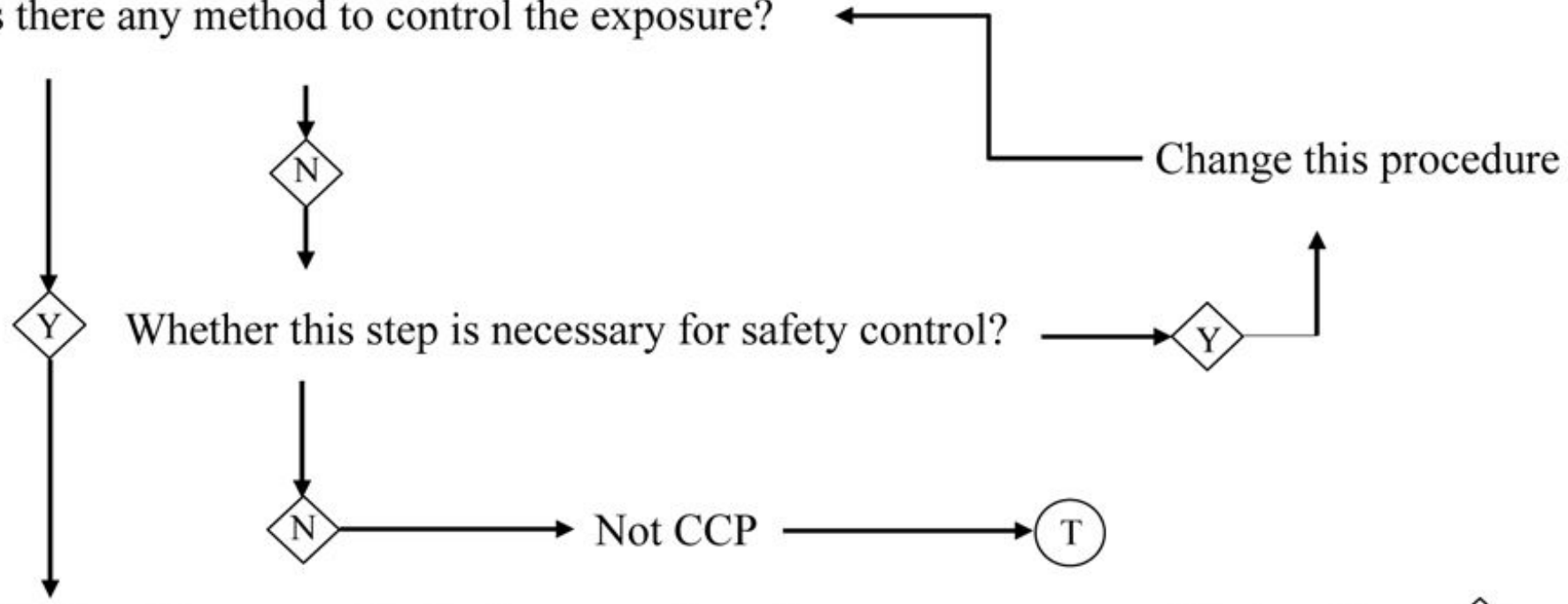

Whether this step is necessary for safety control?
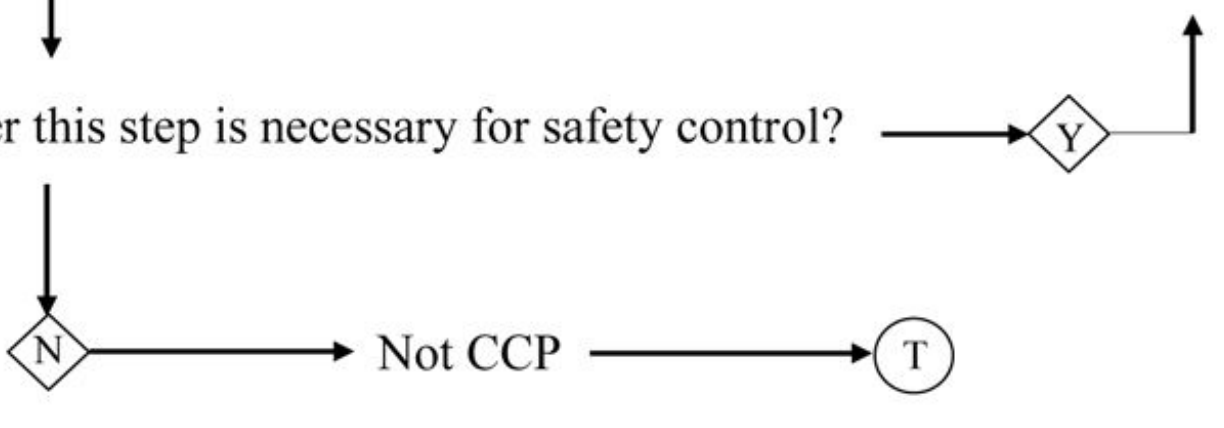

Q3: Whether this step could eliminate or reduce the exposure to acceptable level?

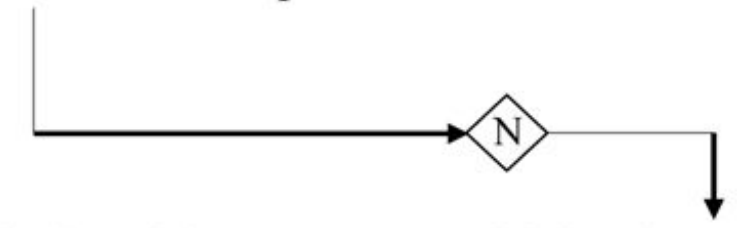

Q4: Whether this exposure could develop or increase exposure level?
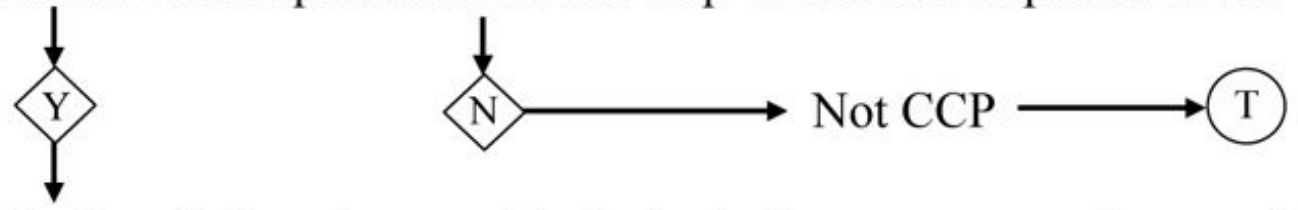

Q5: Whether further steps could eliminate the exposure or decrease it to the safe level?
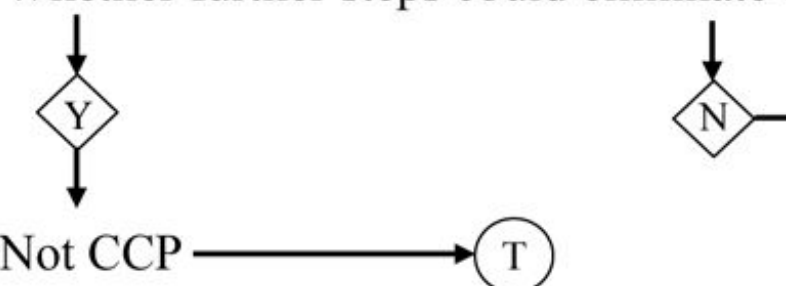

Figure 1

The critical control points decision trees (N: no, Y: yes, CCP: critical control point, T: terminated). 


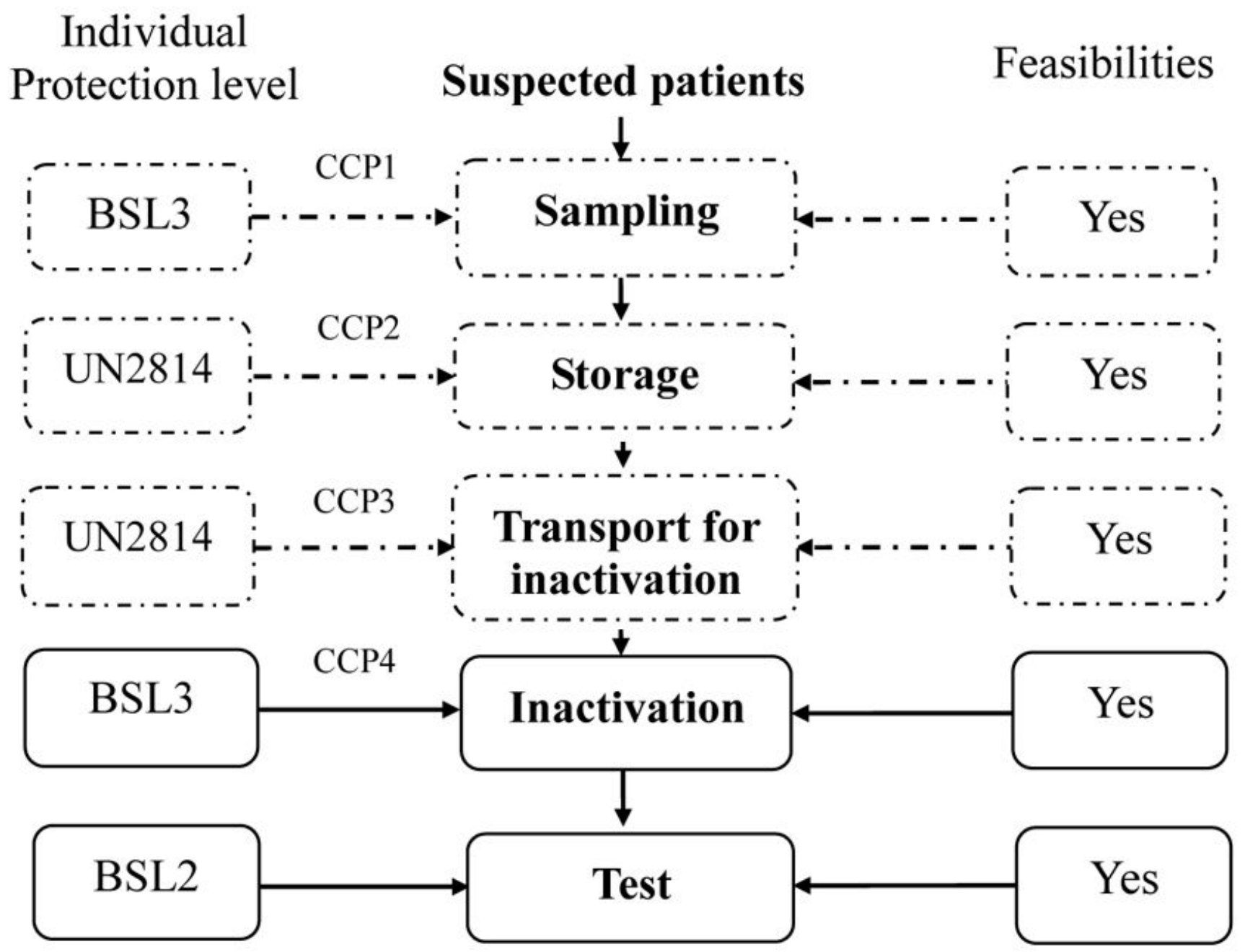

Figure 2

The flow chart for the tests of COVID-19 susceptible patients. The dashed line showed all the operations with different personal protective equipment levels. 


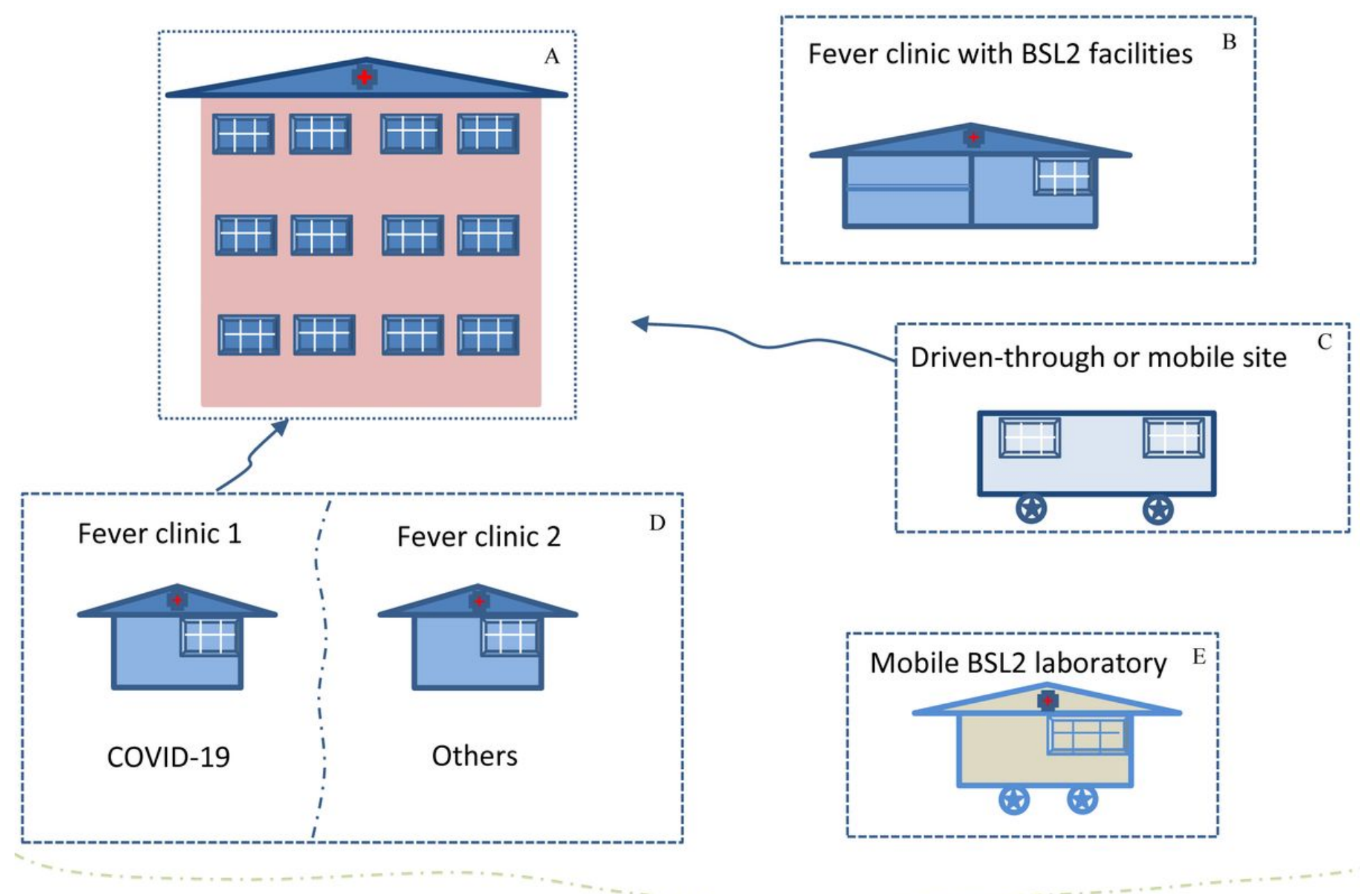

Figure 3

Different response modes of some countries screen and test suspected COVID-19 cases. (A) represents the CDC or other authorized agencies for SARS-CoV-2 RNA testing; (B) represents the fever clinic with BSL2 laboratory like that in the First hospital affiliated with Zhengzhou University; $(C)$ represents the mobile platform or "Drive-through" test sites to enroll COVID-19 patients for RNA tests in USA and Korea; (D) represents the two fever clinics placed as in the Zhongshan hospital affiliated with Fudan University in Shanghai, one is for suspected COVID-19 patients, another is for patents with fever symptoms caused by other reasons; $(E)$ represent the mobile BSL2 laboratory screening suspected COVID-19 cases both from sampling to test. 